\title{
Study of a Short-term Treatment through Referential Activity Linguistic Measures
}

\author{
Rachele Mariani $^{1 \bowtie}$ \& Alessandra De Coro ${ }^{1}$
}

\begin{abstract}
The purpose of the present article is to evaluate in this successful clinical case the Referential Process (Bucci, 1997) in the whole course of the therapeutic process. Objectives: The goals of the study are: to explore the linguistic interaction between patient and therapist; and to analyze specific linguistic patterns marking symbolization and reorganization phases during the sessions. Method: The whole treatment is composed of 14 sessions, each session was transcribed verbatim, all sessions were processed by DAAP software and the following Italian computerized linguistic measures of the referential process were applied: Positive Affects, Negative Affects, Sum Affects, Reflection, Disfluency, Referential Activity Dictionary. Results: The analysis of patient and therapist interactions show a specific linguistic pattern, based on a verbalization of Negative Affects. Through cluster analysis, the whole treatment shows two specific phases; the first is at the beginning when a deep emotional involvement rapidly emerges, along with a high symbolization phase; followed by the second phase characterized by closure and reduction of emotional connections. A specific session "number 7" was also analyzed because of it showed a major pattern change.
\end{abstract}

Keywords: referential activity, linguistic measures, process outcome research

Research in psychotherapy, as underlined by Goldfried and Eubanks-Carter (2004), focuses on three areas: basic research, process research and outcome research. While outcome research can tell us whether therapy works to relieve symptoms or increase the quality of life, process research is needed to provide answers to the question of how therapy works and how changes occur.

According to Kazdin (2009), process research aims at identifying specific moderators responsible for the effectiveness of the treatment and providing direct contributions to clinical work, which could lead to some useful feedback for supervision and the training of therapists.

Moreover, Kazdin (2009) recommends a guiding theory so as to be able to identify chains of causation among the mechanisms of treatment.

The aim of this study is to explore a single case from the point of view of the Multiple Code Theory of Wilma Bucci (Bucci, 1997). Bucci and Maskit (2007)

\footnotetext{
${ }^{1}$ Department of Dynamic and Clinical Psychology, "Sapienza" University of Rome, Italy.

$\bowtie$ Correspondence concerning this paper should be addressed to Rachele Mariani, Via Iberia, 20, 00183 Roma. Email: rachele.mariani@tiscali.it
}

found out that computerized linguistic measures can reach beneath the surface of therapeutic interaction and represent not only patterns of discourse but also some aspects of emotional expressions that speakers may not consciously intend and to which listeners may not explicitly attend. The goal of their research can be seen from two different perspectives: The first consists of developing measures of psychological mediating variables that can be used, along with measures of symptoms and behaviors, as components of treatment outcome studies; the second perspective focuses on the processes of psychotherapeutic treatment, including self-exploration, emotional regulation and interpersonal interaction, as these are manifested in the sessions and developed in the course of treatment, indicated by changes in linguistic variables, as ends in themselves.

\section{Multiple Code Theory and language}

Multiple code theory is a model of cognitive, linguistic, emotional and physical system interactions. The theory proposes an explanation for such interactions in three different conditions regarding connections amongst these systems: their integration in adaptive functioning, their dissociation in psychopathology and, lastly, their 
reintegration in the therapeutic process.

According to Bucci $(1997,2000)$, human beings use three basic ways to elaborate information and build up representations: sub-symbolic modality, non-verbal and symbolic modality and verbal and symbolic modality. The theory of multiple coding is a general theory of emotional information processing that is derived from current work in cognitive psychology and affective neuroscience (Bucci \& Maskit, 2007). The multiple code model concerns the general function of subjective connection between non-verbal-including emotional experience-and verbal experience. The "sub-symbolic system" is responsible for the processes of information depending on global and analogical connection modalities. It operates on continuous dimensions, that is "affective core," according to Emde (1983). The sub-symbolic system is involved in recognizing non-verbal communication expressions, crucial in the relationship between therapist and patient; its codification is expressed by many common actions, such as identifying a familiar voice amongst different voices, doing complicated physical exercises or using special abilities for mathematical, scientific and artistic creative work.

Symbolic representations include visual images, representations from other sensory modalities and language, which allows for abstract thought, reflection, and communication with others. These three systems are interconnected by means of what Bucci calls "referential process" (RP), which is intended to link sub-symbolic experiences with images and words, and vice versa (Bucci, 1997). Thus the RP makes it possible to communicate one's emotional experience to other people, to understand others through their own words and to modulate mutual and/or self-regulation through one's own or other people's words. Images facilitate the connection of multi-modal sub-symbolic experiences into articulated thoughts.

According to the referential process theory (RP), as it operates in psychoanalysis and psychotherapy (Bucci, 1997), change in an emotion schema takes place through sequential occurrence and reiteration of three major phases: Arousal, Symbolizing in Narrative, and Reflection; these phases repeat within and across sessions. In Bucci and Maskit (2007, p.1364) these phases are described as: "arousal-activation of the 'affective core:' The patient struggles to find and make current in the session some sub-symbolic bodily and/or sensory component(s) of a troublesome emotion schema; symbolizing through narrative: Having accessed a problematic emotion schema, the patient next connects the sub-symbolic affective experience to images and words, in the form of proto-typical stories, fantasies, dreams or other narrative material that serve to represent the schema, but whose emotional meaning may not be understood; Reflection: In the shared context of the session, this narrative material is examined, leading to emotional insight and ultimately to change in the problematic schema. Then reiteration of the RP: Effective sessions are likely to be characterized by relatively well organized appearances and reiteration of the RP phases; in less effective work, the process does not play out, or plays out only partially."

\section{Referential Activity}

Referential Activity (RA) was first introduced by Bucci (Bucci \& Freedman, 1978) as a psychological variable designed to measure the degree to which a speaker or writer is connected to non-verbal experience, including affect, as she/he speaks or writes. As a narrative unfolds, RA expresses the degree to which the narrator is reliving the experience so as to generate a description of an episode or image that has the power to evoke corresponding experience in the listener or reader.

The first measure of RA was based on the four scales of Concreteness, Clarity, Specificity and Imagery, derived from features seen as central for vivid and evocative writing (Bucci, 1984). The judges' scores on these four dimensions, on a scale of 0 to 10 , are averaged to obtain an overall RA score. The scales are reliably scored after brief training following instructions given in a manual (Bucci et al., 2004; De Coro \& Caviglia, 2000) and do not depend on clinical expertise.

In RA manual the example of High RA is reported below:

I can't stand fruit with bad spots in it. It gives me the creeps. So I picked up that pineapple and it looked so nice, and then my finger went right through inside it, into this brown, slimy, mushy stuff, and my stomach just turned over (Bucci, Kabasakalian-McKay \& the RA Research Group, 1992, p. 47).

In this example, the speaker is describing an experience in such a way that it is easily brought up in imagination-the visual image of the fruit, the texture of the inside, even the physical repulsion felt by the speaker. There is a feeling of a solid, vivid connection to the memory.

In RA manual the example of Low RA is the following:

I love people and I like to be with people. And right now I feel very bad because I can't be with them and do the things I would like to do. But I'm looking forward to a happier and healthier future and-I don't know what else to say. What else can I talk about? Well-I've had a very eventful life, I think. I've worked practically all my life and I love people (Bucci, Kabasakalian-McKay \& the RA Research Group, 1992, p. 54).

In this example, there are many vague references and a feeling that the speaker is not connected to his/her feelings.

\section{Referential activity computerized measures}

Computerized measures of RA have also been developed for application to large samples and longitudinal studies (see Bucci, \& Maskit 2006, 2008; Mariani, 
Maskit, Bucci, \& De Coro, 2013; De Coro, Andreassi, Mariani, Iberni, Crisafulli, \& Matarrese, 2010). The first computer assisted measure of RA in English, the Computerized Referential Activity (CRA) dictionary, was developed empirically by modeling RA scale scores for large samples of text segments (Mergenthaler \& Bucci, 1999). The second generation computerized RA measure that is available in English, Italian and Spain languages, is the Weighted Referential Activity Dictionary (WRAD; Bucci \& Maskit, 2005; Maskit, 2010; Roussos, Etchebarne, \& Waizmann, 2009; Roussos, \& O'Connell, 2005). As well as the CRA, it was empirically developed by modelling overall average RA based on judges ratings of the four scales; however, it employed a complex weighting procedure that permitted more accurate correspondence to the judges' scores, explained elsewhere (Bucci \& Maskit, 2006; Mariani, Maskit, Bucci, \& De Coro, 2013; Maskit, 2011, 2012; Maskit \& Bucci, 2008; Maskit, Bucci, \& Murphy, 2012; Maskit \& Murphy, 2011).

The Discourse Attributes Analysis Program (DAAP) system is the software used for the application of linguistic measures, which analyzes session texts and compares every word to those included in its dictionary (Maskit, 2010, 2011; Maskit, \& Murphy, 2011). Such a software was designed to read texts, compare them word by word through one or more dictionaries, and calculate a weighted average of the dictionary scores, belonging to each speaker, for each turn of speech, for each text, and for each session. The DAAP software allows the simultaneous application of more dictionaries and enables us to obtain averages for a micro and macro analysis of sessions. The software also produces a type of derived measure, the covariationsbetween two dictionaries and a specific new index of Referential Activity. The linguistic measures of Referential Process were enriched by content analysis dictionaries' unweighted measures.

The unweighted measures (lists of words with a common theme) are commonly used in DAAP analyses (Maskit, Bucci, \& Murphy, 2011). In this paper three specific Italian unweighted measures were applied: affects, reflection, and difluency dictionaries. They are described below in the measures section. Details of the development of the dictionaries are presented elsewhere (Bucci \& Maskit, 2006; Maskit \& Bucci, 2007). ${ }^{1}$

\section{The aim of the study}

The application of referential process linguistic measure to the short-term treatment of $\mathrm{Mr}$. C allows us to analyze micro-interaction as well as on-going macrovariables. As shown in the Special Issue introduction the main aim of this study is to identify the specific results of the linguistic style of Mr. C's referential process in order to compare that result to other process research empirical measures applied to the same treatment (cfr. Special Issue Introduction and Conclusion).

Following Bucci \& Maskit (2007) research method, we intend to analyze the transformation in the spoken language of $\mathrm{Mr}$. C and his therapist in the course of short term treatment. A further main focus is to verify whether linguistic measures follow some specific patterns, highlighting crucial moments of the treatment, which can be defined as changes proper.

Mr. C, in the course of treatment, had achieved a major improvement in symptoms (see Introduction of Special Issue) showing a total symptoms remission. This important result, that is a good outcome, is our starting point, which allows us to identify the linguistic measure transformations taking place in this treatment and the way these transformations can be seen in the multiple code theory framework.

More precisely, we want to find out how language and narrative processes are interrelated, and how these process variables are connected with outcome results. Moreover, the Referential Activity measures allow us to highlight some peculiarities of linguistic expression which can improve the understanding of meaningful interactions between therapist and patient.

Therefore, the goal of this research is to analyze the specific typology of possible inter-subjective exchanges, that is, to detect, if possible, the particular system by which therapist and patient carried out their exchange, bringing about a positive change in the treatment.

According to the multiple code theory, in communication two people not only express themselves verbally, exchanging words and thoughts, but they also reach a deeper and more emotional level, described as sub-symbolic. Bucci believes that if this occurs in every social interaction, then in interaction between patient and therapist this exchange should be stronger (Bucci, 1997).

Our hypothesis is, therefore, to verify whether there is a correlation between the patient and therapists linguistic measures, and to see whether we can draw a specific pattern from these results. In other words, we intend to find out whether the specific pattern found in the correlation between the patient and therapist's linguistic measures can be correlated to a successful treatment.

Moreover, we intend to verify how the communication exchange involves the Disfluency dictionary, since among the dictionaries it is the closest to the sub-symbolic system, and since it represents the arousal phase. Above all, we want to demonstrate how linguistic Disfluency is correlated to the verbal production of patient and therapist.

A second goal of this research is an explorative analysis of whole treatment in order to identify specific patterns characterizing this short term treatment. We want to verify, through cluster analysis, whether this treatment reveals specific patterns of arousal, symbolization and reorganization as happens in long term treatment.

\footnotetext{
${ }^{1}$ Specific information on building unweighted dictionaries is found in Bucci, Maskit, \& Murphy (2011), Mariani, Maskit, Bucci, \& De Coro (2013).
} 
Kingsley (2009) found specific patterns of linguistic measures differentiating the Arousal, Symbolizing and Reorganizing phases in treatment:

(1) the arousal phase is marked by high Disfluency, high non-valence Affect and low Referential Activity;

(2) the symbolizing phase is characterized by high Referential Activity, low Reflection, low Difluency;

(3) the reorganization phase is characterized by high Reflection, low Referential Activity and high Affects.

We want to explore whether that pattern emerges in the whole treatment and whether we can divide the process into specific phases.

\section{Methods}

\section{Measures}

Italian Weighted Referential Activity Dictionary (IWRAD; Mariani, Maskit, Bucci, \& De Coro, 2013). The IWRAD Dictionary contains 9,596 items which cover about $95 \%$ of the text material used to construct and test it. Word examples included in the dictionary, more frequently in the Italian speaking one, with their relative weights are: "che" (that) weight .00423; "non" (not) weight - .0357; "e" (is) weight .0162; "e" (and) weight .0542; "mi" (me) weight .0208; "a" (at) weight .0450; "di" (of) weight .0034; "perché" (because) weight -.01653.

Italian Reflection Dictionary (IREF; Mariani, 2009). Italian Reflection dictionary is composed of words concerning how people think and communicate thoughts. This category includes words referring to cognitive or logical functions (e.g., assume, think, plan) or entities (e.g., reason, cause, consequence); problems or failures of cognitive or logical functions (e.g., confuse); complex verbal communicative functions (e.g., comment, convince, argue, obfuscate); features of mental functioning (e.g., creative, logical). The total sum of IREF words is 908, and it covers 3$4 \%$ of the spoken language (Mariani, 2009).

Italian Disfluency Dictionary (IDF; Bonfanti, Campanelli, Ciliberti, Golia, \& Papini, 2008). The Disfluency dictionary contains a small number of items, exactly 11 words and 2 sounds " $\mathrm{mm}$ " and "ehmm" representing filled pauses with slightly different significance. This small amount of words are commonly used when people are making an effort to communicate, trying to find the right term; in such cases people seem unable to express what they mean.

Here we list all eleven items, which have a 3\% coverage of the Italian language, with a loose translation of the meaning they concretely have in spoken Italian: "quindi" (so), "cioè" (that is), "ehmm" (ehmm), "comunque" (however), "allora" (then), "insomma" (well), "niente" (nothing), "magari" (maybe), "mm" $(\mathrm{mm})$, "vabbe"” (don't care), "boh" (don't know).

Italian Affect Dictionary (IAFF; Rivolta,
Mariani, \& Tagini, 2009). This contains Affect words concerning how people feel and communicate feelings directly. It includes emotion labels (e.g., angry, sad, happy); functions associated with affective arousal (e.g., cried, scream, dared, giggled); functions indicating motivation (e.g., need, try); words implicitly associated with affect (e.g., alone, against); evaluations indicating an affective response, either positive or negative (e.g., cute, gross, lousy, terrific, wonderful, important). A total list of Affect words (IAFFS) is also categorized as Positive Words (IAFFP) and Negative Words (IAFFP). The Affect Dictionary is made up of 1786 words, and covers $5 \%$ of the spoken language

IREF-IWRAD Covariation (Bucci \& Maskit, 2007). Covariations between pairs of measures is a function of smoothing measures over the course of a narrative. DAAP is able to calculate indexes of the extent to which any pair of measures tend to move together or move in opposite directions. This adds an entirely new dimension to text analysis and allows us to measure, for example, the extent to which Referential Activity word use, goes together with Reflection words. The results of studying these covariations across a number of studies have shown that IWRAD, or the extent to which a speaker is telling a story, tends to move in the opposite direction as Reflection (IREF). Reflection (IREF) words are those that refer directly to cognitive processes for example remember, know, think. These two measures are the main markers of the symbolizing phase (IWRAD) and reorganizing phase (IREF) of Bucci's referential process. The consistency of this pattern across studies is striking and is likely to illustrate the different types of language use associated.

The IWRAD Intensity Index (Bucci \& Maskit, 2007). Also known as the Mean High IWRAD (MHIW), in general terms this is a measure of how high RA is, when it is high. MHIW is computed as the mean of the difference between the IWRAD density scores and the IWRAD neutral score of .5 , when this difference is positive. The difference between Mean WRAD, and the WRAD Intensity Index, serves as a measure of the extent to which the speaker is using high RA language.

\section{Procedures}

As already shown (see De Bei, Mariani, \& Rocco, 20913; introduction to the present special issue), Mr. C's case is considered a successful case, due to the results obtained in symptom changes, mentioned above. ${ }^{2}$

Mr. C is a young adult, showing some difficulties in the sexual sphere. He is engaged in a three-year relationship with a girl, his first sexual partner. $\mathrm{He}$ is a brilliant university student. His relationship with his

\footnotetext{
${ }^{2}$ For a more detailed comprehension of the diagnostic assessment, we invite you to read the introduction and the conclusive assessment of this case.
} 
Table 1. Pearson correlations between therapist's and patient's linguistic measures $(N=14)$

\begin{tabular}{lccccccc}
\hline & $\begin{array}{c}\text { IAFFN } \\
\text { patient }\end{array}$ & $\begin{array}{c}\text { IAFFP } \\
\text { patient }\end{array}$ & $\begin{array}{c}\text { IAFFS } \\
\text { patient }\end{array}$ & $\begin{array}{c}\text { IDF } \\
\text { patient }\end{array}$ & $\begin{array}{c}\text { IREF } \\
\text { patient }\end{array}$ & $\begin{array}{c}\text { IWRAD } \\
\text { patient }\end{array}$ & $\begin{array}{c}\text { MHIW } \\
\text { patient }\end{array}$ \\
\hline IAFFN therapist & $.744^{* *}$ & -.268 & .087 & .225 & .018 & .271 & .224 \\
IAFFP therapist & .140 & .419 & $.565^{*}$ & .008 & .145 & .008 & $-.684^{* *}$ \\
IAFFS therapist & $.569^{*}$ & -.052 & .312 & .131 & .213 & .137 & -.208 \\
IDF therapist & -.447 & $.672^{* *}$ & .304 & .156 & -.063 & .138 & -.189 \\
IREF therapist & .148 & .318 & .415 & -.050 & .311 & .093 & .153 \\
IWRAD therapist & .470 & $-.759^{* *}$ & -.492 & -.078 & .170 & .379 & .470 \\
MHIW therapist & .058 & -.299 & -.487 & .051 & .150 & .451 & $.759^{* *}$ \\
\hline
\end{tabular}

Note. IAFFN = Italian Affect Negative. IAFFP = Italian Affect Positive. IAFFS = Italian Affect Sum. IDF = Italian Disfluency. IREF = Italian Reflection. IWRAD = Italian Weighted Referential Activity Dictionary. MHIW = IWRAD Intensity Index.

${ }^{*} p<.05 ;{ }^{* *} p<.01$

girlfriend has some conflicting features, he believes his girlfriend does not understand this problem which he feels extremely responsible for. A few years ago, Mr. C's mother left home because of the restrictive, conflicting relationship with her husband.

Mr. C lives alone in the city where he studies, and occasionally goes to his father's home to pay him a visit. As he does not approve of his mother's decision, his relationship with her is not close.

The analysis of this successful treatment allows us to focus on linguistic transformations occurring in the course of the therapy. The whole treatment of Mr. C was studied by applying referential activity linguistic measures. The referential process linguistic measures dictionaries, described above, were applied on the whole duration of the treatment, made up of 14 sessions transcribed verbatim: 4 consultation sessions, and 10 treatment sessions.

The use of referential dictionaries provides overall measures of single sessions, considering both therapist and patient. Starting from these single session measures, it is possible to observe the macro-process developments and point out some specific relationship aspects that arose during the therapeutic exchange.

\section{Results}

\section{Analysis of therapist-patient interaction}

The application of linguistic measures to session transcripts provides some useful information about therapist-patient interaction. The possibility of observing correlation between patient and therapist allows us to capture the descriptive elements of their interaction. The specific relation amongst linguistic variables represent communicative patterns and show their preferential way of interacting, from which we can draw some particular conclusions about their relationship.

The correlation table shows significant correspondences between therapist and patient specific linguistic measures: in particular, patient's Negative Affects

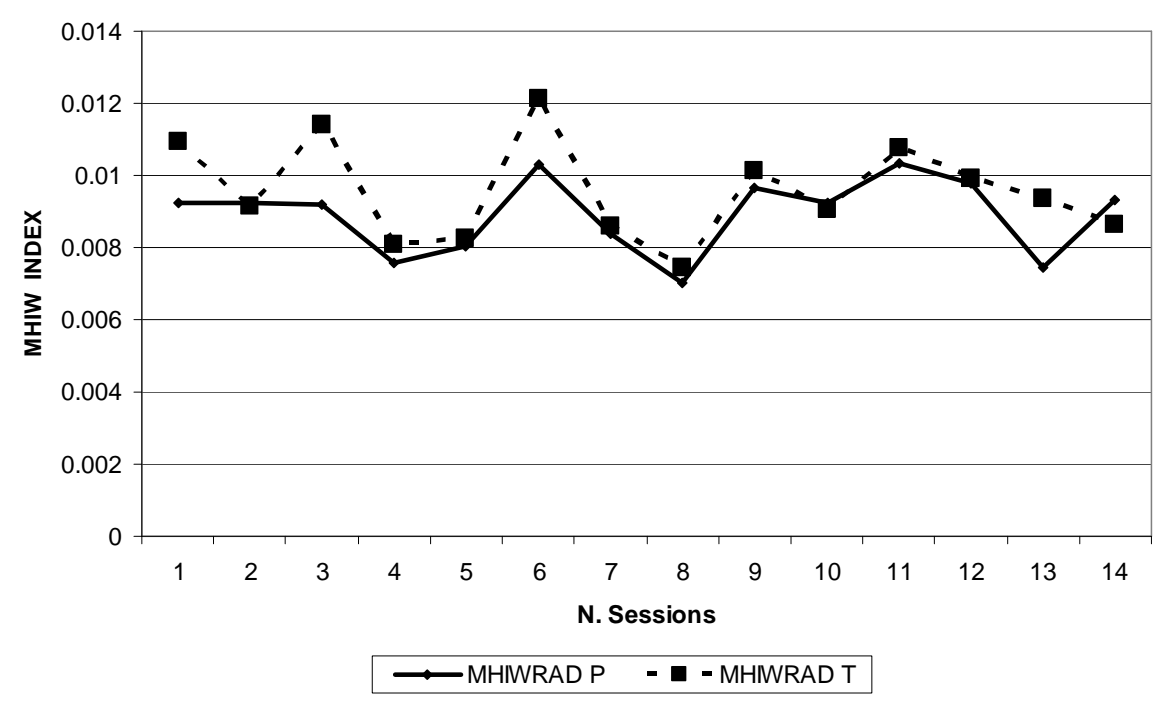

Figure 1. Patient and therapist's Referential Activity Intensity Index (MHIW) over the sessions. 


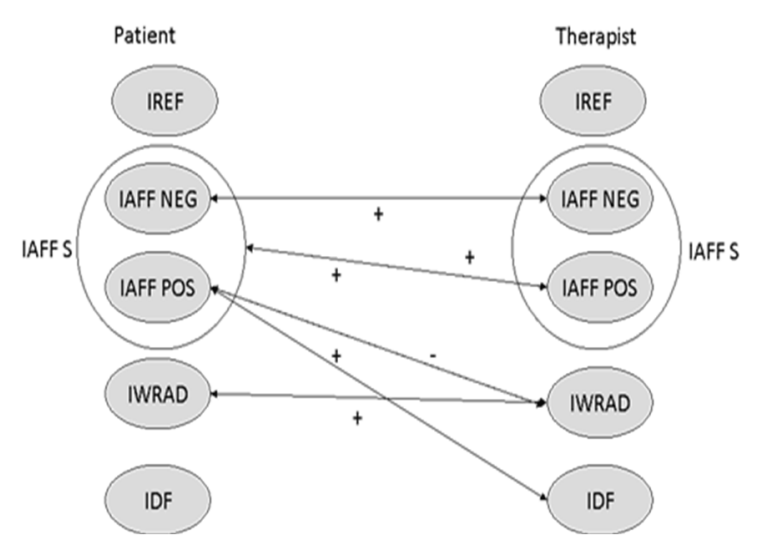

Figure 2. Correlations between patient's and therapist's measures. Positive correlations are indicated by the plus sign. Negative correlation are indicated by the minus sign. IAFF NEG = Italian Affect Negative. IAFF POS = Italian Affect Positive. IAFFS = Italian Affect Sum. IDF $=$ Italian Disfluency. IREF = Italian Reflection. IWRAD $=$ Italian Weighted Referential Activity Dictionary.

correlate linearly with therapist's Negative Affects (IAFFN) and Sum Affects (IAFFS) (Table 1). The whole of the patient's Affects correlate linearly with the therapist's Positive Affects.

As for our hypothesis, to verify whether patient and therapist's Disfluency represents an emotional arousal, we can notice that the patient's Positive Affects (IAFFP) correlate linearly with the therapist's Disfluency (IDF), and correlate inversely with the therapist's Referential Activity (IWRAD).

Such correlations lead us to suppose that patient and therapist mainly use a linguistic code aimed at mentioning and expressing words and feelings. This result is consistent with the therapeutic technique adopted, which uses a direct comparison and expression of feeling as one of the main tools.

The two correlations involving both patient's Affects and Disfluency, together with the therapist's RA, leads
Table 2. Session's cluster membership

\begin{tabular}{ccc}
\hline Session & Cluster & Distance \\
\hline 1 & $\mathrm{~A}$ & .060 \\
2 & $\mathrm{~A}$ & .037 \\
3 & $\mathrm{~A}$ & .071 \\
4 & $\mathrm{~A}$ & .098 \\
5 & $\mathrm{~A}$ & .034 \\
6 & $\mathrm{~A}$ & .028 \\
7 & $\mathrm{~A}$ & .102 \\
8 & $\mathrm{~B}$ & .043 \\
9 & $\mathrm{~B}$ & .060 \\
10 & $\mathrm{~B}$ & .059 \\
11 & $\mathrm{~B}$ & .142 \\
12 & $\mathrm{~B}$ & .051 \\
13 & $\mathrm{~B}$ & .047 \\
14 & $\mathrm{~B}$ & .085 \\
\hline
\end{tabular}

us to suppose that the therapist is particularly focused on the linguistic expression of the patient's Affects.

The therapist's emotional arousal is connected to the patient's affective verbalization; at the same time, it is connected to the therapist's own ability to symbolize his emotional experience in the here and now, through the RA. We can suppose that these correlations drawn from the study, specifically belong to this therapeutic couple, and this particular communication channel may have had a deep influence on the successful outcome of the treatment.

In addition to this affective verbalization pattern, a further correlation element appears, namely that patient and therapist influence each other's Referential Activity Intensity Index. This score expresses the extent of Referential Activity, that is the intensity of the measure. The correlation is linear and positive (Therapist MHIW and Patient MHIW $r=.759, p=.002$ ). In the whole therapeutic process both patient and therapist tune in to each other's Referential Activity, expressing the same level of arousal and emotional symbolization (Figure 1).

Table 3. Linguistic measures means difference (ANOVA) in each cluster

\begin{tabular}{lcccccc}
\hline Linguistic measures & $\begin{array}{c}\text { Cluster } \\
\text { Mean Square }\end{array}$ & Df & $\begin{array}{c}\text { Error } \\
\text { Mean Square }\end{array}$ & Df & F & Sig. \\
\hline IAFFN & .000 & 1 & .000 & 12 & 10.698 & $.007^{* *}$ \\
IAFFP & .000 & 1 & .000 & 12 & .423 & .528 \\
IAFFS & .000 & 1 & .000 & 12 & .001 & .972 \\
IDF & .000 & 1 & .000 & 12 & .274 & .610 \\
IREF & .000 & 1 & .000 & 12 & .012 & .916 \\
IWRAD & .000 & 1 & .000 & 12 & 6.679 & $.024^{*}$ \\
MHIW & .000 & 1 & .000 & 12 & .044 & .837 \\
IREF-IWRAD & .120 & 1 & .005 & 12 & 26.459 & $.000^{* *}$ \\
\hline
\end{tabular}

Note. IAFFN = Italian Affect Negative. IAFFP = Italian Affect Positive. IAFFS = Italian Affect Sum. IDF = Italian Disfluency. IREF = Italian Reflection. IWRAD = Italian Weighted Referential Activity Dictionary. MHIW = IWRAD Intensity Index.

${ }^{*} p<.05 ;{ }^{* *} p<.01$ 
Table 4. Linguistic measures means by cluster

\begin{tabular}{lcc}
\hline $\begin{array}{l}\text { Linguistic } \\
\text { measures }\end{array}$ & Cluster A & Cluster B \\
\hline IAFFN & .013 & .011 \\
IAFFP & .012 & .014 \\
IAFFS & .030 & .030 \\
IDF & .070 & .073 \\
IREF & .033 & .032 \\
IWRAD & .501 & .499 \\
MHIW & .009 & .009 \\
IREF-IWRAD & -.220 & -.034 \\
\hline
\end{tabular}

Note. IAFFN = Italian Affect Negative. IAFFP = Italian Affect Positive. IAFFS = Italian Affect Sum. IDF = Italian Disfluency. IREF = Italian Reflection. IWRAD = Italian Weighted Referential Activity Dictionary. MHIW = IWRAD Intensity Index.

Moreover, it is clear that patient's Referential Activity Intensity Index (Patient MHIW) is linked to the therapist's verbalization of Positive Affects. Here, though, the correlation is inverse $(r=-.684, p=.007)$, the therapist's verbalization of Positive Affects influences negatively the extension of RA and vice versa. This datum proves the correlations highlighted earlier, underlining once more that, in the course of this treatment, emotional verbalization is the main channel of encouragement of inhibition.

We can schematize these correlations in the graph below, showed in Figure 2.

This figure underlines the centrality of the linguistic channel of the patient's affects. This pattern suggests that, in this successful treatment, the main focus is the possibility of recognizing and giving a name to the patient's emotional experience.

The peculiarity of this exchange is the explicit focus on words describing emotions, which is stimulated by the typical technique marking this short-term treat- ment. Although we cannot state that naming affects and recognizing emotions is a therapeutic element in itself for every patient (Bucci \& Maskit, 2007) on this issue tend to move in this direction.

\section{Phases in Mr. C's psychotherapy process}

The second goal of this study is to verify whether Mr. C's. treatment presents the specific linguistic patterns found in Kingsley (2009) differentiated in Arousal, Symbolizing and Reorganizing phases, each phase being characterized by specific linguistic measures as described above. In order to verify this hypothesis, we used a specific statistical analysis, cluster analysis. Clustering is the task of grouping a set of objects in such a way that objects in the same group (called clusters) are more similar (in one sense or another) to each other than to those in other groups (clusters). Using this method we wanted to explore whether in Mr. C's treatment there were three specific clusters representing the patterns found in Kingsley's results. Through cluster analysis with bisecting K-means methods (Savaresi \& Boley, 2001; Steinbach, Karypis \& Kumar, 2000), we investigated whether all sessions were characterized by specific linguistic qualities. K-means method is centroid-based clustering, where clusters are represented by a central vector, which need not necessarily be a member of the data set.

The cluster analysis of all 14 sessions showed the treatment to be divided into just two specific clusters, not three as we predicted. The two specific clusters are: Cluster $\mathrm{A}$ including the first sessions up to session 7 , whereas cluster B includes the conclusive phase of the treatment (Table 2). Therefore, session 7 is crucial, being between the first and the second phase. Analyzing the distances, we can notice that session 7 is the furthest session from Cluster A, as if it highlights a change in the narration style. Moreover, this session has a different length, and it also shows a deeper inter-

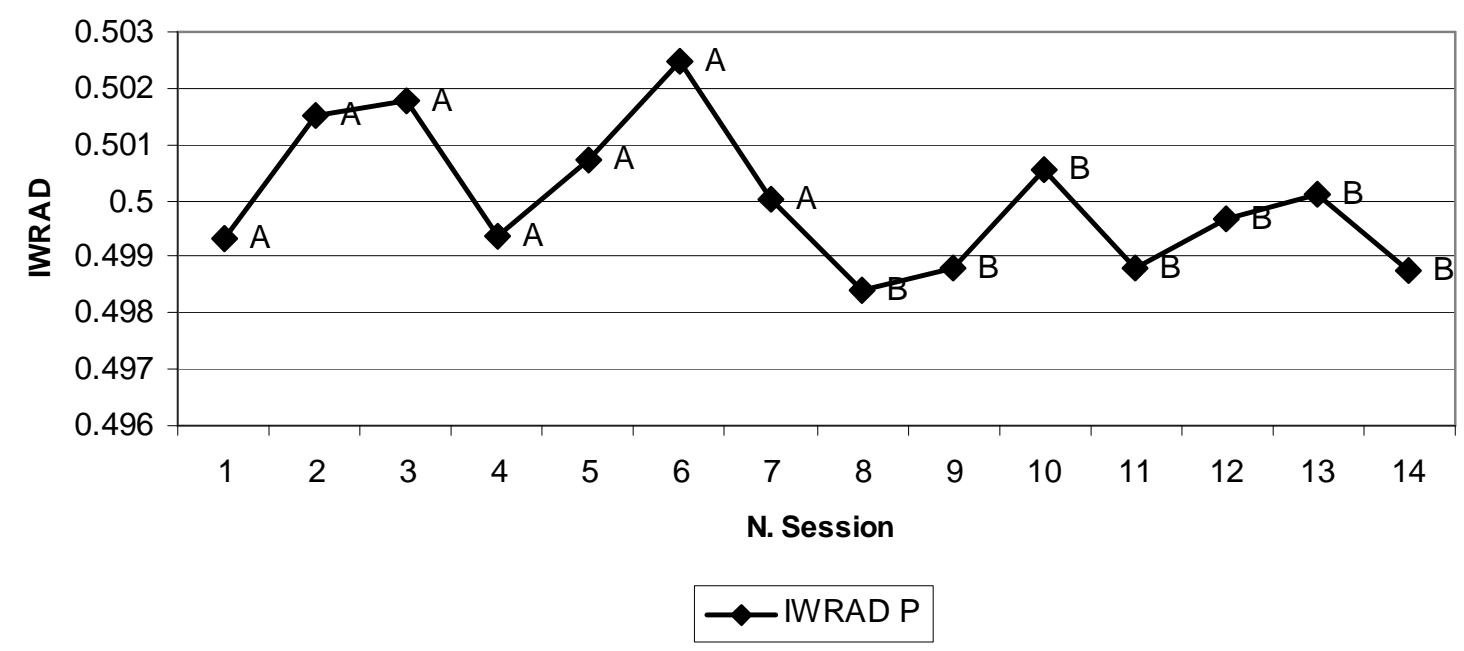

Figure 3. Macroprocess of Referential Activity and belonging clusters over sessions. $\mathrm{A}=$ session belong to cluster $\mathrm{A}$. $\mathrm{B}=$ session belong to cluster B. IWRAD P = Patient's Italian Weighted Referential Activity Dictionary. 
est from both patient and therapist in exploring the emerging content. From a linguistic measures point of view, session 7 represents a turning point in the shortterm treatment. It is significant, then, that descriptive clusters of linguistic variables differ exactly at this point. From a qualitative description of these measures, clusters showed to be different in three variables: Negative Affects, Referential Activity and IREF-IWRAD covariation index (Table 3).

Cluster B has a low IWRAD rate, low Negative Affects and an IREF-IWRAD covariation index close to zero (Figure 3, 4, and 5).

Cluster A, in contrast, has high IWRAD, high Negative Affects, and its IREF-IWRAD covariation index is high negative. Other variables, which do not differ in the two clusters, are shown in Table 3.

If we observe the session from a clinical point of view, through a microanalysis of the linguistic measures development, we can notice an important sequence between therapist and patient. Figures 6 and 7 below show respectively the on-going Referential Activity (Figure 6) of the therapeutic couple and their Negative Affects (Figure 7), through the whole session word by word.

We find that the session starts with an initial phase of symbolization (first RA peak), corresponding to the patient's dream, shown in the text below, which will be the central theme of the session:

[...] it was Mother's day, I was at home, we could $[860,111,28,1]^{3}$ stay together and have an ice cream, let's meet, I want it so much, $[870,121,28,1]$ don't you? And exactly when she $[880,131,28,1]$ sent me this text message, I had just sent another[890,141,28,1] message to her, where... I told her ..[900,151,28,1]. a lie, I just wanted make her feel bad $[910,161,28,1]$, it was true, a bit... and I told her "the night of April $6^{\text {th }}$ I had a dream, [930,181,28,1] I hadn't dreamed for years: I dreamed you were back home, $[940,191,28,1]$ home was the one were I'm living now, but you $[950,201,28,1]$ were the one of many years ago, and I cried while dreaming, $[960,211,28,1]$ because I knew it couldn't be possible that you were there, $[970,221,28,1]$ and you would have gone away, also from the dream anyway, after a few hours. I woke up and I was still crying because that's the mother I miss, now you have changed so much that $[1000,251,28,1]$ I am unwilling to talk to you about my problems, to my mother, $[1010,261,28,1]$ with exclamation marks. ${ }^{4}$

After the narration of the dream, the therapist spurs the patient to think about the maternal abandonment experienced he cannot express (Figure 6), causing a second symbolic arousal, where the patient remembers some of his experiences related to his childhood and his mother.

This second RA peak (Figure 6) determines the verbalization of deep Negative Affects, which make him recall suicidal thoughts, connected with the feelings of powerlessness since, being a child, he could not modify his parents' conflicting relationship.

This session is therefore rich and deeply trans- formative, triggering the opening of emotional schema and, afterwards, their elaboration, followed by a detachment.

The cluster analysis of session 7 highlights the opening up to another phase of the treatment, characterized by a certain decrease in the three linguistic measures (IWRAD, Negative Affects and IREFIWRAD covariation), bringing about a closing of the symbolization and elaboration process, and then, in the following sessions, making the patient step back from his childhood experiences.

\section{Discussion}

The study of patient-therapist relationship proves to be a useful tool in understanding what kind of communication system exists between them. Correlation rates showed that this therapeutic intervention is based on a mutual and correlated activation of the Referential Process. Patient and therapist influence the Referential Activity Intensity Index (MHIW), which can be seen as an attunement in how intense the symbolic process can be. Affect verbalization is also highly represented in this treatment and it seems central in the patient/therapist exchange. The correlation pattern suggests that the patient's Affective language gives rise to symbolic insight on the part of the therapist, who returns new symbolizations to the patient. After these exploratory attempts, this treatment is focused on increasing the patient's ability to verbalize Affect, especially Negative Affect. In fact, the technique used pushes the therapist to confront the patient's feelings and analyze his feeling in the here and now.

According to the cluster analysis results, we can conclude that the first part of the treatment is characterized by a high Referential Activity, which leads to a high immersion in the patient's emotional experiences, and by a high ability to mention Negative Affects, and finally by sessions with an inverse alternation of

\footnotetext{
${ }^{3}$ The numbers in parentheses indicate respectively the word count in the session, the word count in the turn of speech, the speech turns number, speaker.

${ }^{4}$ Italian original transcription: [...] il giorno della festa della mamma, ero a casa, potevamo $[860,111,28,1]$ stare insieme con un gelato. Vediamoci, io lo desidero tanto $[870,121,28,1] \mathrm{e} \mathrm{tu}$ ?" e nello stesso istante in cui lei mi $[880,131,28,1]$ ha mandato questo messaggio io le avevo mandato comunque un $[890,141,28,1]$ altro messaggio .... in cui vabbe', le ho detto su anche $[900,151,28,1]$ un po' una palla, volevo semplicemente farla sentire male un $[910,161,28,1]$ po' era la verità un po' ... e le ho $[920,171,28,1]$ detto la notte del 6 aprile ho fatto un sogno dopo $[930,181,28,1]$ anni che non sognavo più: ho sognato che eri tornata $[940,191,28,1]$ a casa, la casa era quella di adesso ma tu $[950,201,28,1]$ eri quella di diversi anni fa, e ho pianto nel sogno $[960,211,28,1]$ perché sapevo che non era possibile che tu fossi lì $[970,221,28,1]$, e che tu te ne saresti andata anche dal sogno $[980,231,28,1]$ dopo poche ore mi sono svegliato che piangevo ancora perché $[990,241,28,1]$ è quella la madre che mi manca, ora sei talmente $[1000,251,28,1]$ diversa che sono restio a parlarti dei miei problemi, a [1010,261,28,1] mia madre, con i punti esclamativi.
} 


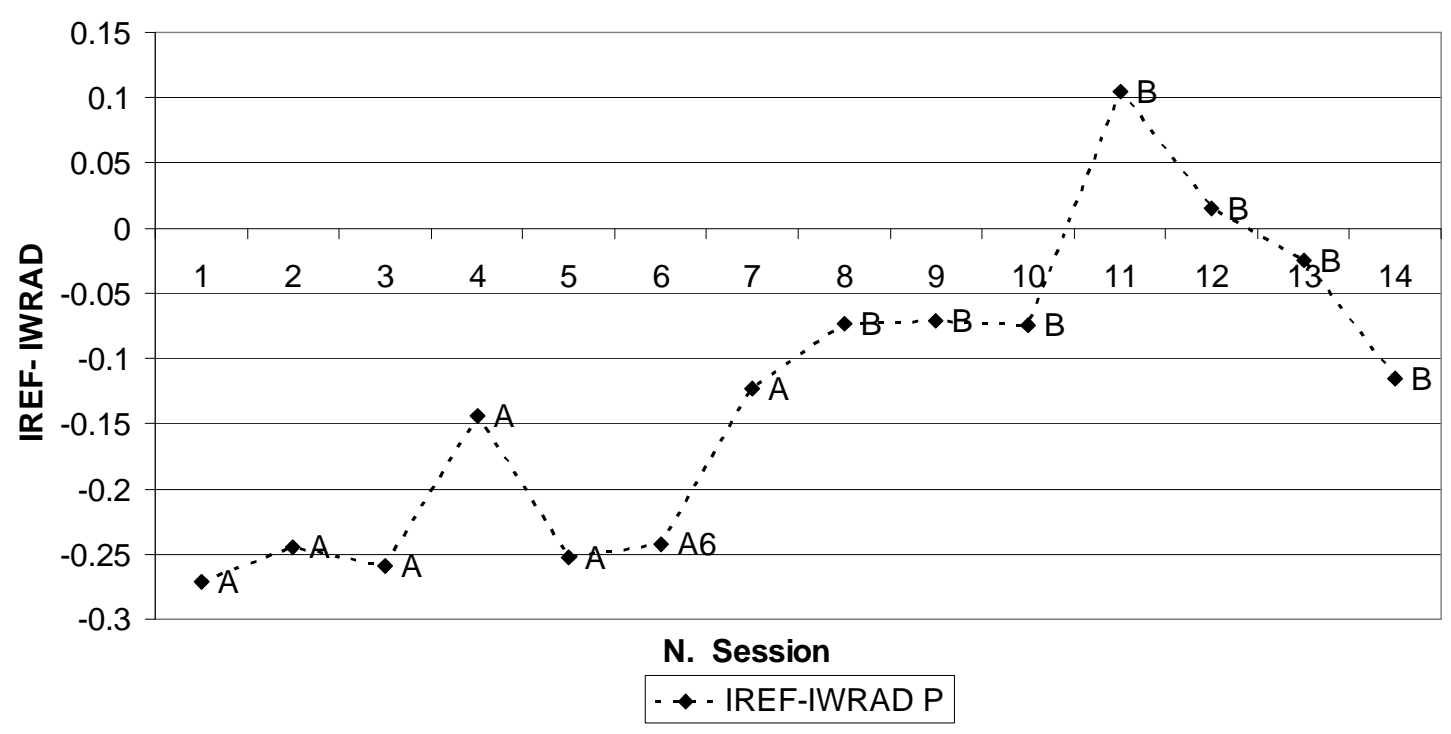

Figure 4. Macroprocess of covariation IREF-IWRAD index and belonging clusters over the sessions. A= session belong to cluster A. B = session belong to cluster B. IREF- IWRAD = Italian Reflection and Italian Weighted Referential Activity Dictionary covariation. IREF-IWRAD P = Patient's Italian Reflection and Italian Weighted Referential Activity Dictionary covariation.

Referential Activity and Reflection words. The last index belongs to clinically relevant sessions, when the narration of patient's experiences comes along with Reflections. The second phase of the treatment has, in contrast, lower rates of these variables, and a lack of emotionally charged narration. In this case, we can suppose it to be a preliminary emotional closing, just before the ending of the treatment.

As regards arousal, symbolization and reorganization patterns (Kingsley, 2009), after the analysis of the whole process, what emerges is that there are only two relevant clusters, not three. Most of all, Cluster A, at the beginning of the treatment, seems to include both symbolization and reorganization phases. As a matter of fact, Cluster A shows high Referential Activity (which typically belongs to the symbolization phase), along with Negative Affects and IREF-IWRAD covariation index (which are the typical indications of the reorganization phase).

Cluster B, on the other hand, has less verbalization of Negative Affects and a good Disfluency level, which generally characterize the arousal phase, or the ending phase of the symbolic process. From this exploration we can see that this short-term treatment quickly allowed the patient to become absorbed into his experiences, enabling the symbolization and the reorganization of the material. This treatment also allowed the patient to switch rapidly to an ending phase, and maybe to an inner activation, in order to conclude the therapy.

The main element obtained from the cluster analysis concerns the first part of the treatment, which is permeated by a strong symbolization and cycles of symbolization/reorganization of the narrative material. In this first phase, that is sessions 1 to 7 , the patient is able to elaborate Negative Affects. This possibility

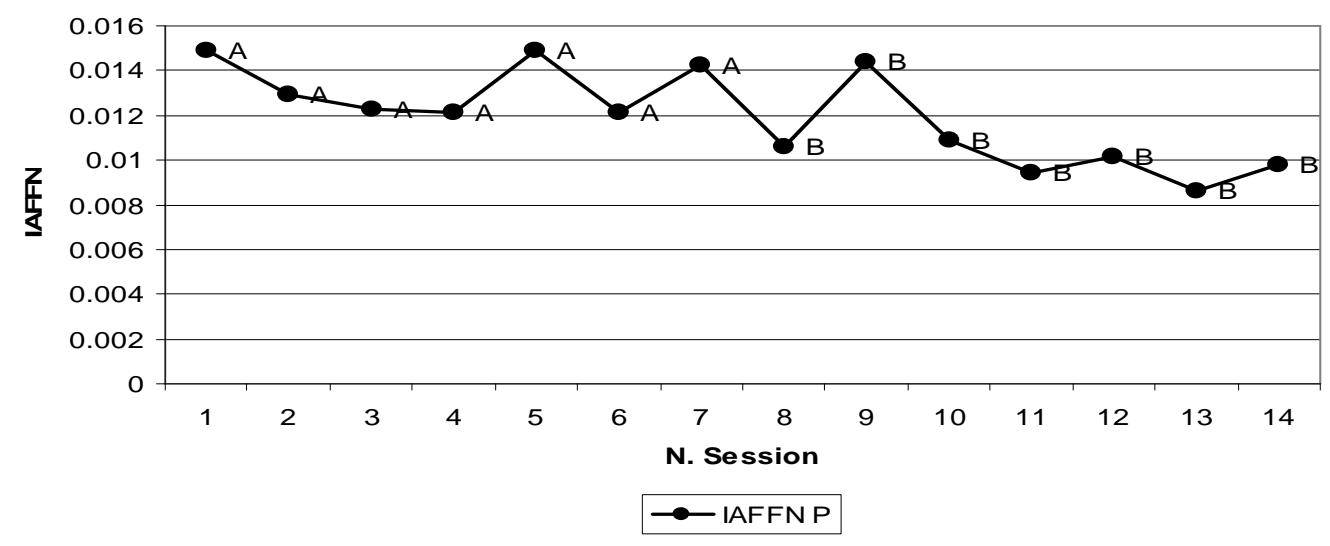

Figure 5. Macroprocess of IAFFN variable and belonging clusters for sessions. $\mathrm{A}=$ session belong to cluster $\mathrm{A}$. $\mathrm{B}=$ session belong to cluster B. IAFFN = Italian Affect Negative. IAFFN P = Patient's Italian Affect Negative. 


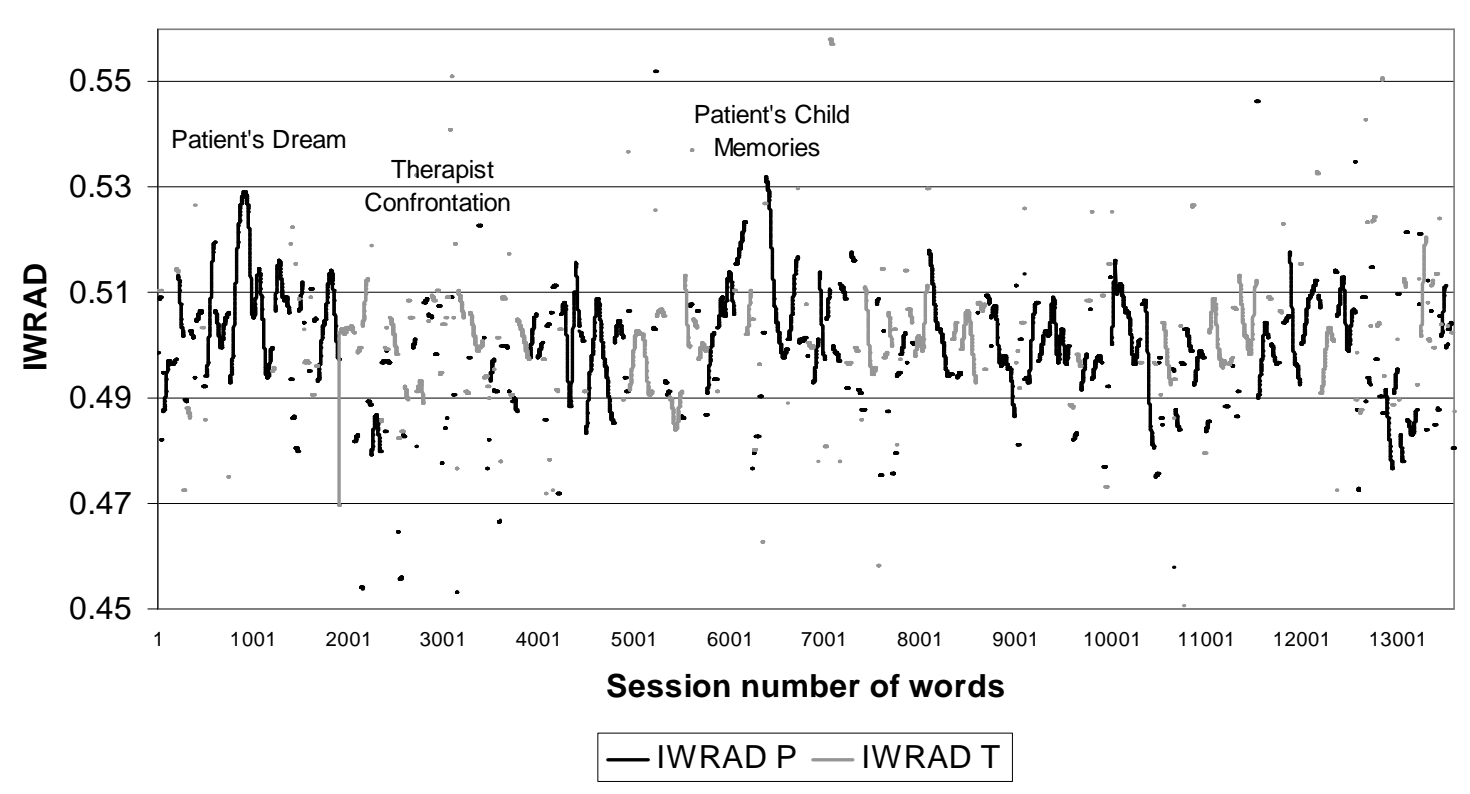

Figure 6. Microanalysis of session 7 Patient and Therapist IWRAD fluctuation. IWRAD = Italian Weighted Referential Activity Dictionary. IWRAD P = Patient's Italian Weighted Referential Activity Dictionary. IWRAD T = Therapist's Italian Weighted Referential Activity Dictionary.

to work directly on symbolized experiences allows both patient and therapist to pass through some delicate contents, closely related to the patient's symptoms. The turning point is session 7 , which has unique characteristics if compared with the other sessions: a larger amount of words, and a longer duration. Linguistic variables show a significant change of direction, occurring after session 7 , as if the symbolization and reorganization processes had come to an end during this special session. The second session phase shows a decrease in Negative Affects and Referential Activity. Thus, the exploration process gives way to the patient's emotional closing.

In other words, the therapeutic change probably occurred during the first seven sessions, and then gave way to the ending of the treatment. The Reflection process strictly belongs to the therapist. The patient is never left alone in his reorganization of contents, being guided by the therapist, who manages the insight process. This phenomenon differs from long-term dynamic treatments, where therapist interventions tend to follow the reorganization process, which is carried out by the patient. This data raises some questions about the differences between short-term and longterm treatments, especially because in long-term psychotherapy, symbolization phases generally occur in the middle of the therapeutic process (Bucci \& Maskit, 2007; Mariani, Maskit, Bucci, \& De Coro, 2013).

\section{Conclusion and research implications}

This case, starting from the study of the Referential Process, shows various elements, useful in understand- ing how a specific intervention worked out. The analysis of the macro-process allowed us to take a snapshot of the whole therapeutic process, extracting qualitatively and quantitatively significant data concerning the linguistic exchange between therapist and patient. Possible data obtained by applying dictionaries to any other single case may differ from the outcomes of the current study, but they may be of interest in making theoretical considerations about the functioning of the clinical exchange.

The application of linguistic measures to Mr. C's whole therapeutic process provided us with interesting outcomes, which could spur further research in this field.

It would indicate that, in this kind of therapeutic process, the emotional activation phase is speeded up, bringing about an immediate symbolization of the patient's experiences. Moreover, it can be seen that the present technique can activate the patient's referential process.

Research by Bucci, Crisafulli, Hart, Hoffman, Kolod, Maskit, and Newirth (2011), shows similar outcomes in the analysis of the Referential Process in a short-term treatment case: the symbolization phase and the narrative of affects occurred in the very first part of the treatment, after which the closing phase and the cognitive reorganization took place.

This research also confirms the validity of Bucci's referential activity methodology, the results seeming to indicate that nonverbal aspects can be extremely important in the description of the process as also found in Rocco (2005), where the linguistic measures have the power to describe what the literature defines as a "relational climate." 


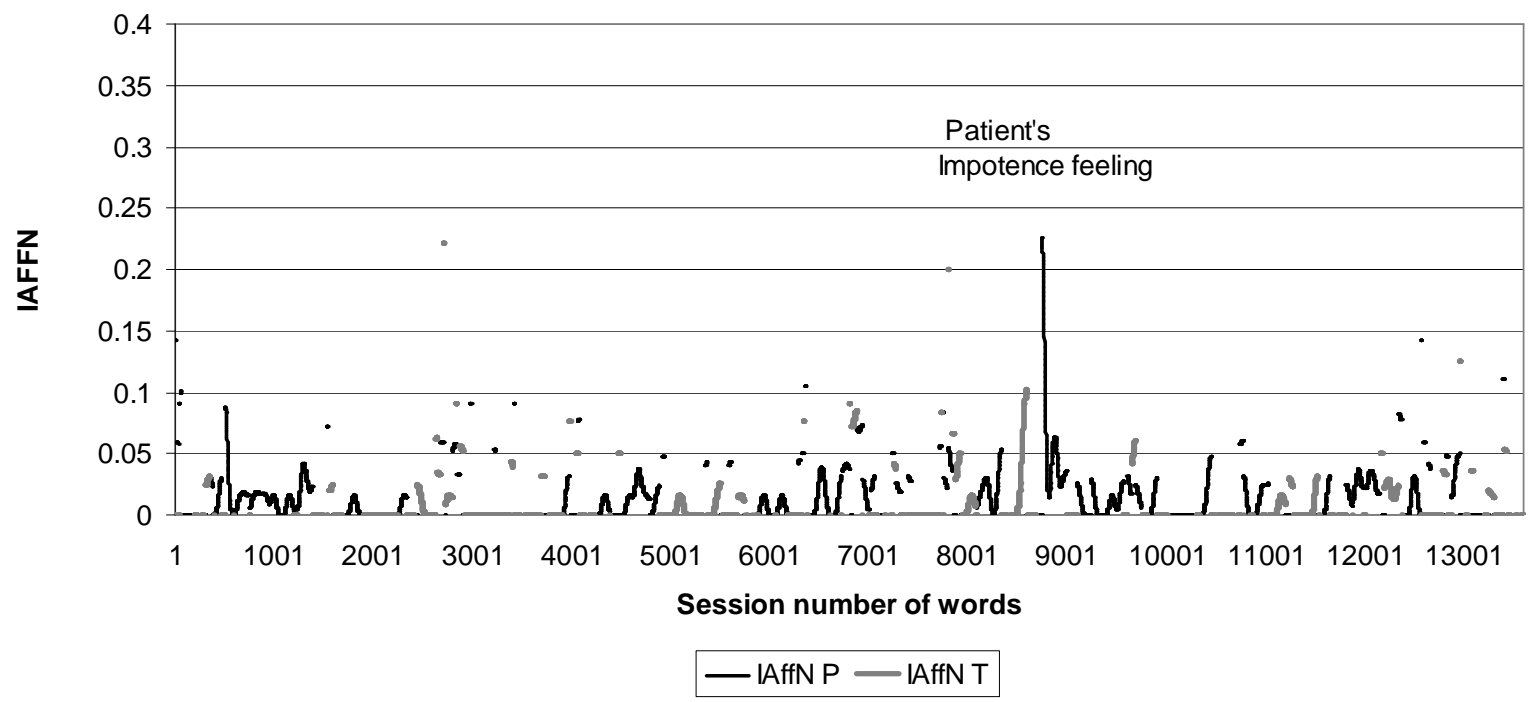

Figure 7. Microanalysis of session 7 patient and Therapist Negative Affect IAFFN measure. IAFF = Italian Affect Negative. IAFF P = Patient's Italian Negative Affect. IAFFN T $=$ Therapist's Italian Negative Affect.

In conclusion, the study of therapeutic macroprocess by means of linguistic measures allows us to highlight the unique characteristics of this exchange, between a specific patient and his/her therapist, detecting those elements that made changes easier.

The specific implication of this kind of research is to identify specific markers in psychotherapy process, to identify moment by moment which phase and what kind of linguistic interaction is going on in any single moment of treatment.

By following the patient and the interactions of the dyad moment by moment, we can see whether or not interventions have their desired impact, allowing for connection to emotional schema, facilitating reflection. The study of therapist and patient linguistic interaction can also allow analysis of countertransference, therapeutic rupture, enactment, and see the specific linguistic transformation that can happen beyond that phenomenon. Also, understanding what happened from one phase to another can help us to understand the way the patient manages to overcome emotional schema dissociations and how the therapist can help the patient in that transformation.

\section{References}

Bonfanti, A. A., Campanelli, L., Ciliberti, A., Golia, G., \& Papini, S. P. (2008, June). Speech Disfluency in spoken language: The Italian Computerized Dictionary (I-Df) and its application on a single case. Paper presented at the SPR International Meeting, Barcelona, Spain.

Bucci, W. (1984). Linking words and things: Basic processes and individual variation. Cognition, 17, 137-153. doi: 00100277(84)90016-7

Bucci, W. (1997). Psychoanalysis and Cognitive Science: A Multiple Code Theory. New York: Guilford Press.

Bucci, W. (2000). The need for a psychoanalytic psychology in the cognitive science field. Psychoanalytic Psychology, 17(2), 203-224. doi: 10.1037/0736-9735.17.2.203

Bucci, W. (2005). Building the interface of research and practice: Achievement and unresolved question. In W. Bucci \& N. Freedman (Eds.), The integration of clinical and research perspectives in psychoanalysis: a tribute to the work of Robert Wallerstein. Psychological Issues Monograph Series: International Universities Press.

Bucci, W., \& Freedman, N. (1978). Language and hand: The dimension of referential competence. Personality, 46(4), 594-622. doi: 10.1111/j.1467-6494.1978.tb00188.x

Bucci, W., \& Kabasakalian-McKay, R. (1992). Instructions for scoring Referential Activity $(R A)$ in Transcripts of Spoken Narrative texts, Ulmer Textbank.

Bucci, W., Kabasakalian, R., \& the Referential Activity Research Group. (2004). Instructions for scoring Referential Activity $(R A)$ in transcripts of spoken narrative texts. Retrieved from http://www.thereferentialprocess.org.

Bucci, W., \& Maskit, B. (2006). A weighted dictionary for Referential Activity. In J. G. Shanahan, Y. Qu \& J. Wiebe (Eds.), Computing Attitude and Affect in Text (pp. 49-60). Dordrecht, The Netherlands: Springer.

Bucci, W., \& Maskit, B. (2007). Beneath the surface of the therapeutic interaction: the psychoanalytic method in modern dress. Journal of the American Psychoanalytic Association, 55(4), 1355-1397. doi: 10.1177/000306510705500412

Bucci, W., \& Maskit, B. (2008).Computerized views of psychoanalytic treatments at increasing magnification. Paper presented at the RAAPA Meeting, NY. Retrieved from www.referentialprocess.org/papers

Bucci, W., Crisafulli, G., Hart, A., Hoffman, L., Kolod, S., Maskit, B., \& Newirth, J. (2011, January). Multiple perspectives on the treatment process in a 9 session treatment. Panel presented at the RAAPA-PPRS Research Forum at the Midwinter Meeting of the American Psychoanalytic Association, New York, NY.

Bucci, W., Kabasakalian, R., \& the Referential Activity Research Group. (2004). Instructions for scoring Referential Activity $(R A)$ in transcripts of spoken narrative texts. Retrieved from http://www.thereferentialprocess.org

De Coro, A., Andreassi, S., Mariani, R., Iberni, E., Crisafulli, V., 
\& Matarrese, A. (2010). La valutazione degli esiti e del processo nelle psicoterapie offerte dai Centri di Salute mentale e da un Centro di Psicologia clinica universitario [Outcome and process assessment in Menthal Healt Institute and University Clinical Center]. Ricerca in Psicoterapia/Research in Psychotherapy, 2(13), 125-146. Retrieved from http:// www.researchinpsychotherapy.net

De Coro, A., \& Caviglia, G. (Eds.). (2000). La valutazione dell'Attività Referenziale [Italian Referential Activity Assessment]. Roma: Kappa

Emde, R. N. (1983). The pre representational self and its affective core. The Psychoanalytic Study of the Child, 38, 165192.

Goldfried, M. R., \& Eubanks-Carter, C. (2004). On the need for a new psychotherapy research paradigm: A comment on Westen, Morrison and Thompson-Brenner (2004). Psychological Bulletin, 130, 669-673. doi: 10.1037/00332909.130.4.669

Kazdin, A. E. (2009). Understanding how and why psychotherapy leads to change. Psychotherapy Research, 19(4-5), 418-428 doi: 10.1080/10503300802448899

Kingsley, G. (2009). The clinical validation of measures of the Referential Process. Unpublished doctoral dissertation, Adelphi University, Derner Institute of Advanced Psychological Studies. ProQuest Dissertations and Theses, Retrieved

from http://search.proquest.com/docview/305124343?acc ountid $=8204$

Mariani, R. (2009). Per uno studio del processo referenziale in psicoterapia: Il Dizionario delle Parole Riflessive (IREF) un indicatore linguistico in relazione all'IWRAD nello studio delle narrative [For a study of referential process in psychotherapy: The Reflection Dictionary (IREF) as a linguistic measure in relation to IWRAD in the study of narratives]. Unpublished doctoral dissertation, La Sapienza University of Rome.

Mariani, R., Maskit, B., Bucci, W., \& De Coro, A. (2013). Linguistic measures of the referential process in three shortterm psychodynamic treatments: The Italian Version. Psychotherapy Research, 23(4), 430-447. doi: 10.1080/ 10503307.2013.794399

Maskit B., \& Murphy, S. (2011) The Discourse Attributes Analysis Program. Retrieved from http://www.thereferentialprocess.org/thediscourse-attributes-analysis-program-daap

Maskit, B., \& Bucci, W. (2008) Computerized views of psychoanalytic treatments at increasing magnifications. Paper presented at the Research Associates of the American Psychoanalytic Association. Retrieved from https:// docs.google.com/presentation/d/135ca_eiXwQc1QYKQ HsztksEcJry5DVPu_2KbSHwZews/edit

Maskit, B. (2011). DAAP Math I: Word count base. Retrieved from
https://docs.google.com/file/d/0B3goZAni6zBkMGIwODExO GUtZDgzNi00ODNjLTk0NjEtZjllZjg1ZjJhMjQ1/edit?pli=1

Maskit, B. (2012) Provisional norms of psychotherapy sessions for measures of the Referential Process. Retrieved from https://sites.google.com/site/referentialprocess/dictionary -measures-and-computer-programs/norms-forpsychotherapy-sessions-for-select-measures

Maskit, B., Bucci, W., \& Murphy, S. (2012). Computerized Language Measures. Retrieved from https://sites. google.com/site/referentialprocess/dictionary-measuresand-computer-programs

Mergenthaler, E., \& Bucci, W. (1999). Linking verbal and nonverbal representations: Computer analysis of Referential Activity. British Journal of Medical Psychology, 72(3), 339-354. doi: 10.1348/000711299160040

Rivolta, L., Mariani, R., \& Tagini, A. (2009, October). The Italian Reflection (IREF) and affect (IAFF) dictionaries as linguistic indicators of mental functioning. Paper presented at the European Meeting SPR, Bolzano, Italy.

Rocco, D. (2005). Analisi degli aspetti paraverbali in una psicoterapia dinamica breve: il metodo dell'Attività Referenziale e l'analisi della Speech Rate [Analysis of paraverbal aspetcs in a short psychodynamic psychotherapy: referential activity method and speech rate]. Ricerca in Psicoterapia, 8(1), 127-147.

Roussos, A., Etchebarne, I., \& Waizmann, V. (2009). The interaction between psychoanalytic interpretations and Referential Activity (S-WRAD): A single case study. Anuario de investigaciones, 16, 95-102.

Roussos, A. J., \& O’Connell, M. (2005).Construcción de un diccionario ponderado en español para medir la Actividad Referencial [Wheighted dictionary building in Spanish language to measure Referential Activity]. Revista del Instituto de Investigaciones de la Facultad de Psicología. UBA, 10(2), 99-119.

Savaresi, S. M., \& Boley, D. L. (2001, April). On the performance of bisecting $K$-means and PDDP. Paper presented at the 1st SIAM Conference on Data Mining, Chicago, IL, USA. Abstracts book, 5, 1-14. Retrieved from http://72.32.205.185/proceedings/datamining/2001/dm0 1_05SavaresiS.pdf

Steinbach, M., Karypis G., \& Kumar V. (2000). A comparison of Document Clustering Techniques. Paper presented at the Proceedings of World Text Mining Conference, KDD2000, Boston.

Received September 26, 2012 Revision received February 23, 2013 Accepted March 3, 2013 